\title{
CORRECTION
}

\section{Correction to: A framework to design vocabulary-based serious games for children with autism spectrum disorder (ASD)}

\author{
Kamran Khowaja ${ }^{1}$ (i) $\cdot$ Siti Salwah Salim ${ }^{2}$
}

Published online: 11 November 2019

(c) Springer-Verlag GmbH Germany, part of Springer Nature 2019

\section{Correction to: Universal Access in the Information Society https://doi.org/10.1007/s10209-019-00689-4}

In the original article, the acknowledgement section is missing. The funding information is given below:

Acknowledgements This research is supported by University of Malaya Research Grant (UMRG) under Equitable Society Research Cluster RP061A-18SB.

Publisher's Note Springer Nature remains neutral with regard to jurisdictional claims in published maps and institutional affiliations.

The original article can be found online at https://doi.org/10.1007/ s10209-019-00689-4.

Kamran Khowaja

kamran.khowaja@gmail.com

1 Isra University, Hyderabad, Pakistan

2 University of Malaya, Kuala Lumpur, Malaysia 